\section{Collaboration, consensus and consideration}

\author{
Eleanor J Tillett
}

\section{COLLABORATION}

This year's British Association of Sport and Exercise Medicine (BASEM) issue for the British Journal of Sports Medicine (BJSM) illustrates what can be achieved when we combine the 'best of the best' experts and research. Collaboration is something we at BASEM are increasingly exploring with our fellow medical and paramedical organisations. This may take the form of combining for conferences, sharing teaching platforms or teaming up for initiatives. While we are generally 'better together', we are also mindful that the voices of individual groups are heard and that we remember the lessons from our recent past.

\section{CONSENSUS}

That international expert researchers spend their time reviewing and condensing the literature for us is something clinicians who access BJSM benefit from again and again. This process is very nicely illustrated by the IOC working group on exercise in pregnancy and I am delighted to be able to include their second (of 5!) instalment (see page 1297). This reviews the effect of exercise on labour and delivery and increases our confidence when dealing with this group of exercises whatever their level of sport. The benefits of physical activity continue to be highlighted in the PEDro synthesis looking at 'Walking Exercise for Chronic Musculoskeletal Pain' (see page 1346) and also in Mears et al's

Correspondence to Eleanor J Tillett, British Association of Sport and Exercise Medicine (BASEM), Suite 1C, Hutton Business Centre, Bentley Road, Doncaster DN5 9QP, UK; ejtillett@doctors.org.uk meta-analysis on 'The Effectiveness of After-School Interventions at Increasing Physical Activity' (see page 1315). And for when exercise is the desired outcome as opposed to the treatment, we have Zellers et al's systematic review of 'Return to Play Post Achilles Tendon Rupture' (see page 1325) which discusses the rate and measures of RTP following this injury.

\section{IN CONSIDERATION OF SCREENING, PROFILING AND INJURY PREVENTION}

That Holy Grail of prevention is explored across a variety of articles in this BASEM-guided issue of BJSM. Two papers by UK authors focus on specific conditions, namely Professor Ian Needleman's call to action for oral health screening (see page 1295) and Professor Sanjay Sharma et al's research into 'The Outcomes of Cardiac Screening in Elite Rugby Players' (see page 1338).

While any screening is complex enough, oral and cardiac health are relatively easy to measure in comparison to defining musculoskeletal health for high performance and injury prevention. The challenges of musculoskeletal profiling and what to do with the data are explored by Drew et al in 'Sports-Related Workload and Injury Risk' (see page 1306), Hegedus et al in 'Physical Performance Tests Predict Injury in National Collegiate Athletes' (see page 1333) and Fonseca et al in 'Complex System Approach for Sports Injuries' (see page 1309). Luckily there is some help at hand from our psychology colleagues as Josh Kazman discusses in his editorial (see page 1290).
SPINES IN THE SPRING-FIRST RATE EDUCATION 30 MARCH...

Finally, a 'save the date' for our Spring Conference on 30 March 2017 which will have a spinal focus. As an appetiser there are a couple of spinal articles included here; an editorial by Ben Darlow (see page 1294) exploring why we may be ignoring management guidelines and a PEDro synthesis on its prevention (see page 1345). You can also get your back pain education via the wildly popular BJSM podcasts. Global stars Peter O'Sullivan and Kieran O'Sullivan (http:// ow.ly/cuKn304kiUX) discuss the management of back pain in separate podcasts. A very easy way to access BJSM podcasts is via the mobile app called 'BJSM'.

\section{END CHALLENGE}

Building on the theme of consensus and collaboration, my readership challenge this year is to look at ways of using collaboration to help translate research into our own work; perhaps by taking one of the articles included in this issue and creating a consensus document on how to deliver the change in practice within an organisation. Given that teamwork is second nature in SEM I am sure this would not be hard! See you at our Spring Conference!

\section{Competing interests None declared.}

Provenance and peer review Not commissioned; internally peer reviewed.

Data sharing statement Not applicable.

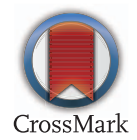

To cite Tillett EJ. Br J Sports Med 2016;50:1289.

Accepted 18 September 2016

Br J Sports Med 2016;50:1289.

doi:10.1136/bjsports-2016-096960 